\title{
Baseline Pulse Pressure, Acute Kidney Injury, and Mortality After Noncardiac Surgery
}

\author{
Adriana D. Oprea, MD,* Frederick W. Lombard, MB, ChB, FANZCA, $†$ Wen-Wei Liu, MSc, $\neq$ \\ William D. White, MSc, † Jörn A. Karhausen, MD, † Yi-Ju Li, PhD, $\neq$ Timothy E. Miller, MB, ChB, FRCA,§ \\ Solomon Aronson, MD, MBA, † Tong J. Gan, MD, MHS, FRCA, \| Manuel L. Fontes, MD,* \\ and Miklos D. Kertai, MD, PhD†
}

\begin{abstract}
BACKGROUND: Increased pulse pressure (PP) is an important independent predictor of cardiovascular outcome and acute kidney injury (AKI) after cardiac surgery. The objective of this study was to determine whether elevated baseline PP is associated with postoperative AKI and 30-day mortality after noncardiac surgery.

METHODS: We evaluated 9125 adult patients who underwent noncardiac surgery at Duke University Medical Center between January 2006 and December 2009. Baseline arterial blood pressure was defined as the mean of the first 5 measurements recorded by the automated record keeping system before inducing anesthesia. Multivariable logistic regression analysis was performed to determine whether baseline PP adjusted for other perioperative risk factors was independently associated with postoperative AKI and 30-day mortality.

RESULTS: Of the 9125 patients, the baseline PP was <40 mm Hg in 1426 (15.6\%), 40-80 $\mathrm{mm} \mathrm{Hg}$ in 6926 (75.9\%), and $>80 \mathrm{~mm} \mathrm{Hg}$ in 773 (8.5\%) patients. The incidence of AKI was $19.8 \%$, which included $8.4 \%$ (151 patients) and $4.2 \%$ (76 patients) who experienced stage II and III AKI, respectively. In the risk-adjusted model for postoperative AKI, elevated baseline PP was associated with higher odds for postoperative AKI (adjusted odds ratio [OR] for every 20 $\mathrm{mm} \mathrm{Hg}$ increase in PP, 1.17; 95\% confidence interval [Cl], 1.10-1.25; $P<.0001)$. Also elevated baseline preoperative PP was significantly associated with mild (stage I; OR, 1.19; 95\% Cl, 1.11-1.27; $P<.0001$ ), but not with more advanced stages of postoperative AKI or with an incremental risk for 30-day mortality.

CONCLUSIONS: We found a significant association between elevated baseline PP and postoperative AKI in patients who underwent noncardiac surgery. However, elevated PP was not significantly associated with more advanced stages of postoperative AKI or 30-day mortality in these patients. (Anesth Analg 2016;XXX:00-00)
\end{abstract}

$\mathrm{P}$ ostoperative acute kidney injury (AKI) remains a serious postoperative complication that affects $6.3 \%$ to $22.4 \%$ of noncardiac surgery patients, ${ }^{1-4}$ with up to $2.2 \%$ requiring renal replacement therapy. ${ }^{4}$ The pathophysiology

From the *Department of Anesthesiology, Yale School of Medicine, New Haven, Connecticut; †Division of Cardiothoracic Anesthesiology and Critical Care Medicine, Department of Anesthesiology, Duke University Medical Center, Durham, North Carolina; ‡Department of Biostatistics and Bioinformatics, Duke University Medical Center, Durham, North Carolina §Division of General, Vascular, and Transplant Anesthesiology, Department of Anesthesiology, Duke University Medical Center, Durham, North Carolina; and ||Department of Anesthesiology, Stony Brook Medicine, Stony Brook, New York.

Accepted for publication July 7, 2016.

Funding: None.

The authors declare no conflicts of interest.

Supplemental digital content is available for this article. Direct URL citations appear in the printed text and are provided in the HTML and PDF versions of this article on the journal's website (www.anesthesia-analgesia.org).

Presented as a poster at the Outcomes and Database Research Poster Session at the American Society of Anesthesiologists Annual Meeting, October 27, 2015.

Adriana D. Oprea, MD, Frederick W. Lombard, MB, ChB, FANZCA, Manuel L. Fontes, MD, and Miklos D. Kertai, MD, PhD, contributed equally to this work, and should be considered co-first and co-senior authors.

Reprints will not be available from the authors.

Address correspondence to Miklos D. Kertai, MD, PhD, Duke University Medical Center, Department of Anesthesiology, Duke University Medical Center, 2301 Erwin Rd, 5693 HAFS Bldg, Durham, NC 27710. Address e-mail to miklos.kertai@duke.edu.

Copyright (C) 2016 International Anesthesia Research Society DOI: 10.1213 /ANE.0000000000001557 of postoperative AKI is complex and involves many factors such as advanced age, male sex, hypertension, diabetes mellitus, higher risk surgery, preexisting renal dysfunction, congestive heart failure, ascites, altered regional blood flow with vasomotor dysfunction, red blood cell transfusion, and inflammatory responses..$^{5-7}$ Postoperative AKI is associated with prolonged hospital stay, increased resource utilization, and high morbidity and mortality. ${ }^{8,9}$ Indeed, patients who develop postoperative AKI are 8 times more likely to die within 30 days after surgery. ${ }^{5}$

Hypertension is a well-characterized cardiovascular risk factor, and elevated systolic and diastolic blood pressure values have been associated with an increased risk for cardiovascular events and mortality. ${ }^{10,11}$ Elevated pulse pressure (PP), that is, the difference between systolic and diastolic pressures, has also been described as a risk factor for increased cardiovascular mortality, particularly in the elderly. ${ }^{12} \mathrm{PP}$ is a measure of the stiffness of conduit vessels and the rate of pressure wave propagation within the arterial tree. ${ }^{13,14}$ Arterial stiffening is associated with aging and causes propagated and reflected waves within the arterial tree to travel much more rapidly, leading to early return of the propagated wave to the central aorta during late systole rather than early diastole. ${ }^{13}$ The increased systolic load that results, coupled with a lower diastolic perfusion pressure and relative intravascular volume depletion, can form the pathophysiologic basis for perioperative organ injury, including cerebral, cardiac, and renal dysfunction. ${ }^{15-19}$ 
We previously reported that an increase in preoperative $\mathrm{PP}$ is associated with an increase in the risk for postoperative renal complications ${ }^{20}$ as well as fatal and nonfatal major cardiovascular events in patients who underwent coronary artery bypass grafting surgery. ${ }^{21}$ In contrast, Mazzeffi et al ${ }^{22}$ and Asopa et $\mathrm{al}^{23}$ found no significant association between increased preoperative PP and an increased risk for allcause mortality and adverse cardiovascular outcomes in patients who underwent lower extremity revascularization. However, these relatively small-scale studies may not have been sufficiently powered to detect the significant differences in outcomes in patients with and without elevated preoperative PP, nor did they investigate a potential association between elevated preoperative PP and postoperative AKI. Here, we conducted a large-scale retrospective study to test our hypothesis that elevated preoperative PP is independently associated with the increased risk for postoperative AKI and 30-day mortality after noncardiac surgery.

\section{METHODS}

\section{Study Population}

The Institutional Review Board for Clinical Investigations at Duke University Medical Center approved this study and waived the requirement for informed consent. Patients in this study were selected from a previously analyzed study of 16,263 patients who underwent noncardiac surgery at Duke University Medical Center (Durham, NC) between January 1, 2006 and December 31, 2009. ${ }^{24}$

In brief, the data set for the parent study was constructed from the Duke Perioperative Electronic Database (Innovian Anesthesia; Draeger Medical Inc, Telford, PA) to determine whether a cumulative duration of low mean arterial pressure (MAP), minimum alveolar concentration (MAC), bispectral index (BIS) (a triple-low state), comorbidities, and type of surgery are associated with increased perioperative and intermediate-term mortality in patients undergoing noncardiac surgery. Patients in the parent study (1) were 18 years or older, (2) had undergone a noncardiac surgical procedure, (3) had no additional procedures during the same study period, (4) were administered a single volatile agent because the primary anesthetic (5) had essential clinical data needed to estimate the Cleveland Clinic Risk Index score, ${ }^{25}$ and (6) had at least 10 min or longer duration of MAP, BIS, and endtidal MAC monitoring; or all 3 parameters had to be monitored for at least $75 \%$ of the intraoperative period.

In the present study, we excluded patients with missing information on (1) history of cardiac medication use, (2) preinduction systolic and diastolic blood pressures, (3) preoperative and postoperative serum creatinine, or (4) preoperative hemoglobin concentration. Thus, 9125 patients were included in the current analyses.

General anesthesia for adult noncardiac surgery at Duke University Medical Center is usually induced with propofol (1-1.5 mg/kg) and fentanyl (100-150 $\mu \mathrm{g})$, and maintained with one of the potent volatile agents-desflurane, sevoflurane, or isoflurane-in an oxygen/nitrous oxide or oxygen/ air mixture, with an inspiratory oxygen concentration of at least 50\%. Further, for patients requiring general anesthesia, volume- or pressure-controlled ventilation with $5 \mathrm{~cm}$ $\mathrm{H}_{2} \mathrm{O}$ of positive end-expiratory pressure is used. End-tidal anesthetic gas concentration is monitored throughout the case, and postoperative care is provided in the postoperative anesthesia recovery unit or in the intensive care unit, as indicated.

\section{Data Collection}

For the present study, we collected data on potential clinical determinants of postoperative AKI and all-cause mortality, including patient characteristics, American Society of Anesthesiologists (ASA) physical status classification system category, preoperative and intraoperative medication use, intraoperative blood transfusions, preoperative hemoglobin values, pre- and postoperative serum creatinine values, duration of surgery, and durations of low and high intraoperative MAP. Intraoperative hypotension (MAP $<55 \mathrm{~mm} \mathrm{Hg}$ ) or hypertension (MAP >100 mm Hg) was defined according to the methodology of Reich et al. ${ }^{26}$ In addition, we collected information on the Cleveland Clinic Risk Stratification Index score, which is based on the International Classification of Disease and Procedures, Ninth Revision (ICD-9), and billing codes. ${ }^{25}$ As previously described, ${ }^{24,25}$ the Risk Stratification Index was developed as a method of predicting 30-day and long-term mortality in patients undergoing noncardiac surgery. We calculated its value for each patient based on published methodology validated with published example standards. ${ }^{25}$

Per institutional protocol, we measured serum creatinine preoperatively in the Duke Clinical Pathology Laboratory and for the first 10 days postoperatively or until discharge, whichever came first, using a method previously described. ${ }^{27}$ The normal range was $0.4-1.0 \mathrm{mg} / \mathrm{dL}(31-76 \mu \mathrm{mol} / \mathrm{L})$ for women and 0.6-1.3 mg/dL (46-99 $\mu \mathrm{mol} / \mathrm{L})$ for men.

Baseline blood pressure was defined as the average of the first 5 intraoperative values recorded when the patient was awake and mildly sedated but before the anesthesia induction. These values were obtained through noninvasive oscillometric measurements, and, in cases where this was not available, invasively through an arterial catheter. The mean systolic blood pressure, mean diastolic blood pressure, and pulse pressure (PP; mean systolic blood pressure minus mean diastolic blood pressure) were calculated for each patient. ${ }^{20,21}$

BIS and end-tidal anesthesia gas concentration values were recorded at 1-min intervals, as described previously. ${ }^{24}$ Age-adjusted MAC values were calculated according to the Nickalls and Mapleson charts, ${ }^{28}$ which include the adjustment for nitrous oxide. Intraoperative MAP values were recorded at 1-min intervals when an arterial catheter was used or at 2- to 5-min intervals when noninvasive blood pressure was measured oscillometrically. As described earlier, ${ }^{24}$ MAP values were considered artifactual and were excluded when the recorded value was $<30 \mathrm{~mm} \mathrm{Hg}$ or $>250 \mathrm{~mm} \mathrm{Hg}$. When MAP values for a given minute were missing, they were interpolated linearly between the preceding and following values. However, if MAP values were missing for more than 15 consecutive minutes, the patient was excluded.

\section{Classification of Outcomes}

AKI defined as a binary outcome variable was the primary outcome chosen and was ascertained and categorized according to the Kidney Disease: Improving Global 
Outcomes (KDIGO) clinical practice guidelines ${ }^{29}$ with modification because of the absence of urine output data. In brief, serum creatinine was measured preoperatively (baseline) 3 days before surgery and for the first 10 days postoperatively or until discharge, whichever came first. A diagnosis of postoperative AKI was made when the postoperative serum creatinine rose $\geq 50 \%$ in the first 10 postoperative days or increased $0.3 \mathrm{mg} / \mathrm{dL}(26.5 \mu \mathrm{mol} / \mathrm{L})$ using a rolling $48-\mathrm{h}$ window across the 10-day postoperative period. Stages of postoperative AKI were assigned as follows: stage 1-risk: meeting the AKI criteria but not as severe as stages 2 and 3; stage 2-injury: 2.0- to 2.9-fold rise in serum creatinine ( $100 \%$ to $200 \%$ increase) within 10 days; stage 3-failure: $\geq 3$.0-fold rise in serum creatinine $(\geq 200 \%$ increase) within 10 days or $\geq 4 \mathrm{mg} / \mathrm{dL}(353.6 \mu \mathrm{mol} / \mathrm{L})$ increase.

The secondary outcome was all-cause mortality occurring within 30 days after surgery. Survival information was obtained from records of return hospital encounters, and the National Cancer Registry, the National Death Index, and the Social Security Death Index, as previously described. ${ }^{24}$

\section{Statistical Analysis}

Continuous variables are presented as means $( \pm \mathrm{SD})$ or medians (interquartile range), and categorical variables are presented as group frequencies and percentages. Kruskal-Wallis or $\chi^{2}$ tests were used for descriptive comparisons as appropriate.

The association of baseline preoperative PP with postoperative AKI defined as a binary outcome variable was assessed through multivariable logistic regression analysis. Univariable associations with $P<.20$ were evaluated by means of a forward stepwise technique to derive the final multivariable logistic regression model containing variables with $P<.05$. Baseline preoperative PP was evaluated for nonlinearity by using empirical logit plots on the deciles of the baseline preoperative PP and by using a test method whereby baseline preoperative PP was divided into quintiles and the linear trend across those quintiles were examined and subsequently tested in the final multivariable logistic regression model containing variables with $P<.05$.

In a subsequent analysis, a stepwise multivariable proportional odds model (ordinal logistic regression) testing variables with a $P<.05$ from the final multivariable logistic regression model was constructed to determine the association between baseline preoperative PP and the different stages of postoperative AKI, respectively. The proportional odds assumption was assessed with a score test.

The association between baseline preoperative PP and 30-day mortality, as our secondary outcome variable, was assessed by multivariable logistic regression analysis. Again, univariable associations with $P<.20$ were evaluated by means of a forward stepwise technique to derive the final multivariable logistic regression model containing variables with $P<.05$.

Further, we quantified the discriminatory power of final multivariable logistic regression models using the c-index, which equals the area under the receiver operating characteristics curve and ranges from 0.5 (performance by chance) to 1.0 (optimal performance). ${ }^{30}$ The model fit of the final multivariable logistic regression models was further assessed using the Hosmer-Lemeshow goodness-of-fit test. ${ }^{31}$ Odds ratios and the corresponding 95\% confidence limits are reported. All analyses were performed using SAS Version 9.3 (SAS Institute Inc, Cary, NC).

\section{RESULTS}

\section{Patient Characteristics}

The mean age $( \pm$ SD) of the 9125 patients was $55.9 \pm 15.3$ years. Twenty-four percent of the study population was African American, and 4746 patients (52\%) were men. Based on the ASA Physical Status Classification System, 3\% of the cohort was classified as category P1, 40.9\% P2, 50.7\% P3, $5.3 \% \mathrm{P} 4$, and $0.05 \% \mathrm{P} 5$. Eight percent of the patients underwent emergency surgery.

The median Cleveland Clinic Risk Index score was -0.462 (interquartile range, -1.441 to 0.443 ). The mean values of the baseline blood pressure components were systolic blood pressure $(131.6 \pm 21.2 \mathrm{~mm} \mathrm{Hg})$, diastolic blood pressure $(75.7 \pm 13.7 \mathrm{~mm} \mathrm{Hg})$, and MAP $(94.4 \pm 14.7 \mathrm{~mm} \mathrm{Hg})$; and the mean PP was $55.9 \pm 16.5 \mathrm{~mm} \mathrm{Hg}$. The mean preoperative hemoglobin concentration was $13.05 \pm 2.14 \mathrm{~g} / \mathrm{dL}$, and the median preoperative serum creatinine was $0.9 \mathrm{mg} / \mathrm{dL}$ (interquartile range, 0.8-1.2). The most frequently used preoperative cardiovascular medications were $\beta$-blockers $(23 \%)$ and antiplatelet medications (23\%), followed by diuretics $(20 \%)$.

The most common disease diagnosis category (ICD-9) was cancer ( $49.4 \%$ of patients); $22.7 \%$ had disease in the digestive system, and $20 \%$ had disease in the musculoskeletal system. The most frequently performed procedures (ICD-9) involved the digestive system (28.1\%), the musculoskeletal system $(21.9 \%)$, and the male genital organs $(11.3 \%)$. Demographic and clinical characteristics of the patients stratified according to low, normal, and high baseline PP are presented in Table 1 . There were several significant differences between groups, including age, male sex, ASA physical status classification system category, Cleveland Clinical Risk Index score, previous and intraoperative cardiovascular medication use, and intraoperative characteristics.

\section{Postoperative Acute Kidney Injury}

The overall incidence of postoperative AKI was 19.8\% $(n=1805)$. For the purposes of this study, these patients were divided into 3 groups according to baseline PP: $<40 \mathrm{~mm} \mathrm{Hg}$ $(11.3 \%, \mathrm{n}=204) ; 40-80 \mathrm{~mm} \mathrm{Hg}(75.3 \%, \mathrm{n}=1360)$; and $>80$ $\mathrm{mm} \mathrm{Hg}(13.4 \%, \mathrm{n}=241)$. Univariable predictors of postoperative AKI are shown in Supplemental Table 1 (Supplemental Digital Content, http://links.lww.com/AA/B494). The results of the univariable analysis showed that an elevated baseline preoperative PP was associated with a higher odds for postoperative AKI (OR, 1.35 for every $20 \mathrm{~mm} \mathrm{Hg}$ increase in PP; 95\% CI, 1.28-1.44; $P<.0001)$.

After adjusting for differences in baseline and clinical characteristics, results of the multivariable analysis showed that an elevated baseline preoperative PP was associated with a higher odds for postoperative AKI (Table 2). Testing the assumption of linearity of baseline preoperative PP revealed that the relationship between baseline preoperative PP and postoperative AKI was linear. The final multivariable model for postoperative AKI showed good discriminatory ability and good fit (c-index $=0.705$; overall goodness-of-fit Hosmer-Lemeshow test, $\chi^{2}=9.39 ; P=.397$ ).

Of the 1805 patients with postoperative AKI, 87.4\% $(\mathrm{n}=1578), 8.4 \%(\mathrm{n}=151)$, and $4.2 \%(\mathrm{n}=76)$ met criteria for 
Table 1. Baseline Clinical Characteristics $(n=9125)$

\begin{tabular}{|c|c|c|c|c|c|c|c|}
\hline \multirow[b]{2}{*}{ Characteristics } & \multicolumn{6}{|c|}{ Pulse Pressure Categories } & \multirow[b]{2}{*}{$P^{a}$} \\
\hline & \multicolumn{2}{|c|}{$\begin{array}{c}<40 \mathrm{~mm} \mathrm{Hg} \\
(\mathrm{n}=1426 ; 15.6 \%)\end{array}$} & \multicolumn{2}{|c|}{$\begin{array}{c}40-80 \mathrm{~mm} \mathrm{Hg} \\
(\mathrm{n}=6926 ; 75.9 \%)\end{array}$} & \multicolumn{2}{|c|}{$\begin{array}{c}>80 \mathrm{~mm} \mathrm{Hg} \\
(\mathrm{n}=773 ; 8.5 \%)\end{array}$} & \\
\hline Age $(y)$ & 1426 & $49 \pm 13$ & 6926 & $56 \pm 15$ & 773 & $68 \pm 13$ & $<.0001$ \\
\hline Male sex & 1426 & $762(53.4)$ & 6926 & 3696 (53.4) & 773 & $288(37.3)$ & $<.0001$ \\
\hline Race & 1426 & & 6926 & & 773 & & .0002 \\
\hline White & & $982(68.9)$ & & 4982 (71.9) & & $532(68.8)$ & \\
\hline Black & & 341 (23.9) & & $1606(23.2)$ & & $210(27.2)$ & \\
\hline All other & & $103(7.2)$ & & $338(4.9)$ & & $31(4.0)$ & \\
\hline ASA category & 1426 & & 6926 & & 773 & & $<.0001$ \\
\hline $\mathrm{P} 1$ & & $62(4.3)$ & & $211(3.0)$ & & $4(0.5)$ & \\
\hline $\mathrm{P} 2$ & & $677(47.5)$ & & 2929 (42.3) & & $127(16.4)$ & \\
\hline P3 & & $614(43.1)$ & & 3453 (49.9) & & $558(72.2)$ & \\
\hline P4 & & $72(5.0)$ & & $330(4.8)$ & & $83(10.7)$ & \\
\hline P5 & & $1(0.1)$ & & $3(0.0)$ & & $1(0.1)$ & \\
\hline Emergency surgery & 1426 & $98(6.9)$ & 6926 & $539(7.8)$ & 773 & $83(10.7)$ & .005 \\
\hline Cleveland Clinic Risk Index & 1426 & $-0.40[-1.30 ; 0.40]$ & 6926 & $-0.50[-1.50 ; 0.40]$ & 773 & $0.0[-0.9 ; 1.10]$ & $<.0001$ \\
\hline \multicolumn{8}{|l|}{ Preoperative laboratory results } \\
\hline Creatinine $(\mathrm{mg} / \mathrm{dL})$ & 1426 & $0.9[0.8 ; 1.1]$ & 6926 & $0.9[0.8 ; 1.2]$ & 773 & $1.0[0.8 ; 1.4]$ & $<.0001$ \\
\hline Hemoglobin (g/dL) & 1426 & $13 \pm 2$ & 6926 & $13 \pm 2$ & 773 & $12 \pm 0.0$ & $<.0001$ \\
\hline \multicolumn{8}{|l|}{ Preoperative medications } \\
\hline$\alpha$-Receptor blockers & 1426 & $90(6.3)$ & 6926 & $331(4.8)$ & 773 & $63(8.2)$ & $<.0001$ \\
\hline Angiotensin-converting enzyme inhibitors & 1426 & $158(11.1)$ & 6926 & $1068(15.4)$ & 773 & $190(24.6)$ & $<.0001$ \\
\hline Angiotensin receptor blockers & 1426 & $67(4.7)$ & 6926 & $621(9.0)$ & 773 & $120(15.5)$ & $<.0001$ \\
\hline Antiplatelet medications & 1426 & $225(15.8)$ & 6926 & $1576(22.8)$ & 773 & 293 (37.9) & $<.0001$ \\
\hline$\beta$-Blockers & 1426 & $212(14.9)$ & 6926 & $1541(22.2)$ & 773 & $350(45.3)$ & $<.0001$ \\
\hline Calcium channel blockers & 1426 & $90(6.3)$ & 6926 & $810(11.7)$ & 773 & $193(25.0)$ & $<.0001$ \\
\hline Cholesterol-lowering medications & 1426 & $10(0.7)$ & 6926 & $93(1.3)$ & 773 & $16(2.1)$ & 0.022 \\
\hline Diuretics & 1426 & $223(15.6)$ & 6926 & $1340(19.3)$ & 773 & $255(33.0)$ & $<.0001$ \\
\hline Nitroglycerine & 1426 & $30(2.1)$ & 6926 & $239(3.5)$ & 773 & $63(8.2)$ & $<.0001$ \\
\hline \multicolumn{8}{|l|}{ Intraoperative variables } \\
\hline $\begin{array}{l}\text { Cumulative duration of time with MAP }<55 \\
\qquad \mathrm{~mm} \mathrm{Hg}(\min )\end{array}$ & 1426 & $0.0[0.0 ; 3.8]$ & 6926 & $0.0[0.0 ; 3.9]$ & 773 & $0.0[0.0 ; 3.2]$ & .35 \\
\hline $\begin{array}{l}\text { Cumulative duration of time with MAP }>100 \\
\qquad \mathrm{~mm} \mathrm{Hg} \text { (min) }\end{array}$ & 1426 & $8.1[0.5-28.4]$ & 6926 & $13.8[3.2 ; 37.4]$ & 773 & $24.0[9.4 ; 49.9]$ & $<.0001$ \\
\hline Epinephrine & 1426 & $26(1.8)$ & 6926 & 76 (1.1) & 773 & $11(1.4)$ & .07 \\
\hline Nitroglycerine & 1426 & $25(1.8)$ & 6926 & $231(3.3)$ & 773 & $68(8.8)$ & $<.0001$ \\
\hline Nitroprusside & 1426 & $7(0.5)$ & 6926 & $25(0.4)$ & 773 & $8(1.0)$ & .03 \\
\hline Norepinephrine & 1426 & $40(2.8)$ & 6926 & $131(1.9)$ & 773 & $16(2.1)$ & .09 \\
\hline Phenylephrine & 1426 & $759(53.2)$ & 6926 & $3483(50.3)$ & 773 & $397(51.4)$ & .12 \\
\hline Crystalloid (mL) & 1426 & $2125[1375 ; 3000]$ & 6926 & 1715 [1050; 2625] & 773 & $2075[1325 ; 2900]$ & $<.0001$ \\
\hline Colloid (mL) & 1426 & $0.0[0.0 ; 500]$ & 6926 & $0.0[0.0 ; 500]$ & 773 & $0.0[0.0 ; 500]$ & .0001 \\
\hline Red blood cell transfusion & 1426 & $94(6.6)$ & 6926 & $506(7.3)$ & 773 & $88(11.4)$ & .0001 \\
\hline Fresh frozen plasma transfusion & 1426 & 27 (1.9) & 6926 & $126(1.8)$ & 773 & $16(2.1)$ & .89 \\
\hline Platelet transfusion & 1426 & 15 (1.1) & 6926 & $55(0.8)$ & 773 & $10(1.3)$ & .27 \\
\hline Cryoprecipitate & 1426 & $5(0.4)$ & 6926 & $4(0.1)$ & 773 & $1(0.1)$ & .01 \\
\hline Bispectral index & 1426 & $45.5 \pm 8.4$ & 6926 & $45.7 \pm 8.1$ & 773 & $45.2 \pm 8.0$ & .12 \\
\hline \multicolumn{8}{|l|}{ Intraoperative variables } \\
\hline MAC (\%) & 1426 & $0.7 \pm 0.2$ & 6926 & $0.7 \pm 0.2$ & 773 & $0.7 \pm 0.2$ & $<.0001$ \\
\hline Duration of surgery (min) & 1426 & $206[149 ; 272]$ & 6926 & 203 [149; 275] & 773 & $196[136 ; 268]$ & $<.0001$ \\
\hline Year of surgery & 1426 & & 6926 & & 773 & & $<.0001$ \\
\hline 2006 & & $206(14.4)$ & & $821(11.9)$ & & $84(10.9)$ & \\
\hline 2007 & & $443(31.1)$ & & $2023(29.2)$ & & $213(27.6)$ & \\
\hline 2008 & & $492(34.5)$ & & 2129 (30.7) & & $237(30.7)$ & \\
\hline 2009 & & $285(20.0)$ & & $1953(28.2)$ & & 239 (30.9) & \\
\hline ICD-9 diagnosis category ${ }^{b}$ & 2282 & & 10951 & & 1327 & & $\mathrm{P}^{\mathrm{b}}$ \\
\hline Infectious and parasitic & & $25(1.1)$ & & $74(0.7)$ & & $9(0.7)$ & \\
\hline Neoplasm & & $659(28.9)$ & & $3482(31.8)$ & & $366(27.6)$ & \\
\hline $\begin{array}{l}\text { Endocrine, nutritional, metabolic, and } \\
\text { immunity disorders }\end{array}$ & & $53(2.3)$ & & 337 (3.1) & & $97(7.3)$ & \\
\hline Blood and blood-forming organs & & $15(0.7)$ & & $108(1.0)$ & & $7(0.5)$ & \\
\hline Mental & & $4(0.2)$ & & $30(0.3)$ & & $3(0.2)$ & \\
\hline Nervous systems and sense organs & & 30 (1.3) & & 119 (1.1) & & $8(0.6)$ & \\
\hline Circulatory system & & $71(3.1)$ & & $461(4.2)$ & & $150(11.3)$ & \\
\hline Respiratory system & & $53(2.3)$ & & $264(2.4)$ & & $44(3.3)$ & \\
\hline Digestive system & & $380(16.7)$ & & $1561(14.3)$ & & $133(10.0)$ & \\
\hline Genitourinary system & & $165(7.2)$ & & $886(8.1)$ & & $132(9.9)$ & \\
\hline
\end{tabular}




\begin{tabular}{|c|c|c|c|}
\hline \multicolumn{3}{|c|}{ Pulse Pressure Categories } & \multirow[b]{2}{*}{$P^{a}$} \\
\hline $\begin{array}{c}<40 \mathrm{~mm} \mathrm{Hg} \\
(\mathrm{n}=1426 ; 15.6 \%)\end{array}$ & $\begin{array}{c}40-80 \mathrm{~mm} \mathrm{Hg} \\
(\mathrm{n}=6926 ; 75.9 \%)\end{array}$ & $\begin{array}{c}>80 \mathrm{~mm} \mathrm{Hg} \\
(\mathrm{n}=773 ; 8.5 \%)\end{array}$ & \\
\hline $12(0.5)$ & $45(0.4)$ & 0 & \\
\hline $19(0.8)$ & $65(0.6)$ & $6(0.5)$ & \\
\hline 333 (14.6) & $1363(12.4)$ & $121(9.1)$ & \\
\hline $27(1.2)$ & $113(1.0)$ & $5(0.4)$ & \\
\hline 27 (1.2) & $113(1.0)$ & $5(0.4)$ & \\
\hline $107(4.7)$ & 432 (3.9) & $51(3.8)$ & \\
\hline $229(10.0)$ & $1293(11.8)$ & $161(12.1)$ & \\
\hline $2(0.1)$ & $14(0.1)$ & $1(0.1)$ & \\
\hline 98 (4.3) & $304(2.8)$ & $33(2.5)$ & \\
\hline 1426 & 6926 & 773 & $<.0001$ \\
\hline $5(0.4)$ & $28(0.4)$ & $5(0.6)$ & \\
\hline $1(0.1)$ & $6(0.1)$ & 0 & \\
\hline 46 (3.2) & 218 (3.1) & $81(10.5)$ & \\
\hline 458 (32.1) & $1921(27.7)$ & $183(23.7)$ & \\
\hline $1(0.1)$ & $2(0.02)$ & $1(0.1)$ & \\
\hline $28(2.0)$ & $174(2.5)$ & $23(3.0)$ & \\
\hline 0 & $1(0.01)$ & $1(0.1)$ & \\
\hline $93(6.5)$ & $6(0.1)$ & 0 & \\
\hline $43(3.0)$ & $164(2.4)$ & $26(3.4)$ & \\
\hline 45 (3.2) & $248(3.6)$ & 38 (4.9) & \\
\hline 137 (9.6) & 869 (12.5) & $22(2.8)$ & \\
\hline $316(22.2)$ & $1506(21.7)$ & $173(22.4)$ & \\
\hline 41 (2.9) & 202 (2.9) & $11(1.4)$ & \\
\hline $2(0.1)$ & $21(0.3)$ & $1(0.1)$ & \\
\hline 69 (4.8) & $312(4.5)$ & $63(8.2)$ & \\
\hline 121 (8.5) & 475 (6.9) & $60(7.8)$ & \\
\hline $12(0.8)$ & $58(0.8)$ & $4(0.5)$ & \\
\hline
\end{tabular}

\section{Characteristics}

Pregnancy, childbirth, puerperium

Skin and subcutaneous tissue

Musculoskeletal system

Congenital anomalies

Conditions originating in the perinatal

period

Symptoms, signs, ill-defined

Injury and poisoning

External causes

Supplementary factors

ICD-9 primary procedure category

Miscellaneous diagnostic and therapeutic

Obstetrical

Cardiovascular system

Digestive system

Ear

Endocrine

Eye

Female genital organs

Hemic and lymphatic system

Integumentary system

Male genital organs

Musculoskeletal system

Nervous system

Nose, mouth, and pharynx

Respiratory system

Urinary system

Other procedures and interventions

Values are mean $\pm \mathrm{SD}$, median [interquartile range], or percentages (numbers).

Abbreviations: ASA, American Society of Anesthesiologists; BIS, bispectral index; ICD-9, International Classification of Diseases and Procedures, Ninth Revision; MAC, minimum alveolar concentration; MAP, mean arterial pressure; P, Physical Status Classification.

${ }^{a}$ Descriptive comparisons were made using Kruskal-Wallis test or $\chi^{2}$ tests, as appropriate. $P$ values presented in the table are for overall comparisons among all groups and do not reflect comparisons between specific groups.

${ }^{b}$ All diagnoses per patient were counted, resulting in a higher number of diagnoses than patients. Hence, no $P$ value was calculated for diagnoses

Table 2. Pulse Pressure as a Multivariable Predictor of Postoperative Acute Kidney Injury, and Severity of Postoperative Acute Kidney Injury

\begin{tabular}{|c|c|c|c|c|c|c|c|c|}
\hline \multirow[b]{3}{*}{ Predictors } & \multirow{2}{*}{\multicolumn{2}{|c|}{$\begin{array}{c}\text { Patients With } \\
\text { Postoperative AKI } \\
\text { Compared to Patients } \\
\text { Without Postoperative AKI } \\
\end{array}$}} & \multicolumn{6}{|c|}{$\begin{array}{l}\text { Patients With Different Stages of Postoperative AKI } \\
\text { Compared With Patients Without Postoperative AKI }\end{array}$} \\
\hline & & & \multicolumn{2}{|c|}{ Stage I, n = 1578} & \multicolumn{2}{|c|}{ Stage II, n = 151} & \multicolumn{2}{|c|}{ Stage III, n = 76} \\
\hline & $\begin{array}{l}\text { Odds Ratio } \\
\text { (95\% Cl) }\end{array}$ & $\boldsymbol{P}$ & $\begin{array}{l}\text { Odds Ratio } \\
\text { (95\% Cl) }\end{array}$ & $P$ & $\begin{array}{l}\text { Odds Ratiob } \\
\text { (95\% Cl) }\end{array}$ & $\boldsymbol{P}$ & $\begin{array}{l}\text { Odds Ratiob } \\
\text { (95\% Cl) }\end{array}$ & $\boldsymbol{P}$ \\
\hline $\begin{array}{l}\text { Baseline pulse pressure, } \\
\text { per 20-mm Hg increase }\end{array}$ & 1.17 (1.10-1.25) & $<.0001$ & $1.19(1.11-1.27)$ & $<.0001$ & $1.11(0.92-1.35)$ & .28 & $0.96(0.73-1.26)$ & .78 \\
\hline
\end{tabular}

Abbreviation: AKI, acute kidney injury.

Odds ratios $(95 \% \mathrm{Cl})$ are adjusted for baseline and clinical predictors using:

amultivariable logistic regression analysis or

${ }^{b}$ multinomial multivariable logistic regression analysis as appropriate. For details on significant baseline and clinical predictors, see Supplemental Tables 1 and 2.

stages I, II, and III AKI, respectively. When we attempted to use a stepwise multivariable proportional model (ordinal logistic regression) to determine the association between elevated baseline preoperative PP and the different stages of postoperative AKI, the results of the score test was significant $(P<.0001)$ indicating that the proportional odds assumption was not satisfied. Thus, it was necessary to construct a stepwise multinomial multivariable logistic regression model to determine the association between elevated baseline preoperative PP and the stages of postoperative AKI, adjusted for baseline and clinical characteristics identified in the multivariable logistic regression model for predicting postoperative AKI as a binary outcome variable. Elevated baseline preoperative PP was significantly associated with mild (stage I; OR, 1.19; 95\% CI, 1.11-1.27; $P<.0001$ ), but not with more advanced stages of postoperative AKI (Table 2 and Supplemental Table 2 [Supplemental Digital Content, http://links.lww.com/AA/B494]) compared with patients without postoperative AKI.

\section{Perioperative Mortality}

Overall, the 30-day mortality rate was $1.14 \%$ of the 9125 study patients. Of the 104 patients who died, 15.4\% $(\mathrm{n}=16)$ had a baseline PP $<40 \mathrm{~mm} \mathrm{Hg} ; 74 \%(\mathrm{n}=77)$ had a baseline 
PP of 40-80 mm Hg; and 10.6\% $(\mathrm{n}=11)$ had a baseline PP > $80 \mathrm{~mm} \mathrm{Hg}$. Univariable predictors of 30-day mortality are shown in Table 3. Many of the baseline and clinical characteristics were associated with an increased risk for 30-day mortality, as well as postoperative AKI. However, the result of the univariable analysis showed that a higher preoperative baseline PP was not associated with an increased risk for 30-day mortality (OR, 1.13; 95\% CI, 0.91-1.42; $P=.27$ ), and thus, this parameter was not included in the multivariable regression analysis, as described in our statistical analysis.

In multivariable analysis, age at surgery, ASA physical status classification system category, higher Cleveland Clinic Risk Index score, intraoperative norepinephrine use, platelet transfusion, and postoperative AKI were significant predictors of 30-day mortality (Table 3). Higher preoperative hemoglobin concentration and more recent year of surgery were associated with decreased 30-day mortality. Further, the risk for 30-day mortality increased by $68 \%$ (OR, 1.68; 95\% CI, $1.28-2.19 ; P<.0002)$ in patients with more severe postoperative AKI. The final multivariable logistic regression model for 30-day mortality showed excellent discriminative ability (c-index $=0.929$ ). The overall goodness-of-fit HosmerLemeshow test showed a good fit $\left(\chi^{2}\right.$ test $\left.=6.788 ; P=.559\right)$.

\section{DISCUSSION}

Our findings demonstrated that in patients undergoing noncardiac surgery, an elevated preoperative PP is a significant predictor of postoperative AKI. In this cohort, AKI was common, occurring in $19.8 \%$ of patients, with the majority developing stage I disease (87.1\%). Consistent with previous reports AKI was significantly associated with an incremental risk for 30-day mortality. However, elevated preoperative PP did not increase the risk for 30-day mortality.

Several large population-based studies have reported that elevated PP is a risk factor for cardiovascular morbidity and
Table 3. Univariable and Multivariable Predictors of 30-Day Mortality

\begin{tabular}{|c|c|c|c|c|}
\hline \multirow[b]{2}{*}{ Predictors } & \multicolumn{2}{|l|}{ Univariable } & \multicolumn{2}{|c|}{ Multivariable } \\
\hline & Odds Ratio (95\% Cl) & $P$ & Odds Ratio (95\% Cl) & $P$ \\
\hline Age at surgery, per year increase & $1.04(1.03-1.06)$ & $<.0001$ & $1.03(1.02-1.05)$ & $<.0001$ \\
\hline Male sex & $1.12(0.76-1.65)$ & .57 & & \\
\hline \multicolumn{5}{|l|}{ Race } \\
\hline Black & 1.0 & & & \\
\hline White & $0.93(0.60-1.45)$ & .76 & & \\
\hline All other & $0.17(0.02-1.24)$ & .08 & & \\
\hline ASA category, per category increase & $8.30(5.98-11.48)$ & $<.0001$ & $1.97(1.33-2.93)$ & .0008 \\
\hline Emergency surgery & $3.39(2.12-5.42)$ & $<.0001$ & & \\
\hline Cleveland Clinic Risk Index, per 1-point increase & $1.87(1.74-2.02)$ & $<.0001$ & $1.49(1.35-1.65)$ & $<.0001$ \\
\hline Preoperative hemoglobin, per $1-\mathrm{g} / \mathrm{dL}$ increase & $0.63(0.58-0.69)$ & $<.0001$ & $0.85(0.76-0.95)$ & .004 \\
\hline Baseline pulse pressure, per 20-mm Hg increase & $1.13(0.91-1.42)$ & .27 & & \\
\hline \multicolumn{5}{|l|}{ Preoperative medications } \\
\hline$\alpha$-Receptor blockers & $3.62(2.10-6.21)$ & $<.0001$ & & \\
\hline Angiotensin-converting enzyme inhibitors & $1.56(0.98-2.48)$ & .06 & & \\
\hline Angiotensin receptor blockers & $0.41(0.15-1.11)$ & .08 & & \\
\hline Antiplatelet medications & $2.03(1.36-3.03)$ & .0005 & & \\
\hline$\beta$-Blockers & 2.69 (1.82-3.97) & $<.0001$ & & \\
\hline Calcium channel blockers & $1.44(0.86-2.44)$ & .17 & & \\
\hline Cholesterol-lowering medications & $1.49(0.36-6.12)$ & .57 & & \\
\hline Diuretics & $2.44(1.64-3.65)$ & $<.0001$ & & \\
\hline Nitroglycerine & $2.87(1.48-5.57)$ & .002 & & \\
\hline \multicolumn{5}{|l|}{ Intraoperative variables } \\
\hline $\begin{array}{l}\text { Cumulative duration of time with MAP }<55 \mathrm{~mm} \mathrm{Hg} \text {, } \\
\text { per 10-min increase }\end{array}$ & $1.18(1.09-1.27)$ & $<.0001$ & & \\
\hline $\begin{array}{l}\text { Cumulative duration of time with MAP }>100 \mathrm{~mm} \mathrm{Hg} \text {, } \\
\text { per 10-min increase }\end{array}$ & $0.92(0.85-0.99)$ & .03 & & \\
\hline Epinephrine & $12.08(6.90-23.55)$ & $<.0001$ & & \\
\hline Nitroglycerine & $1.98(0.91-4.30)$ & .08 & & \\
\hline Nitroprusside & $7.21(2.19-23.76)$ & .0012 & & \\
\hline Norepinephrine & $21.69(13.74-34.24)$ & $<.0001$ & $2.43(1.37-4.29)$ & .002 \\
\hline Phenylephrine & $2.19(1.44-3.33)$ & .0002 & & \\
\hline Crystalloid, per 500-mL increase & $0.92(0.85-1.005)$ & .07 & & \\
\hline Colloid, per 500-mL increase & $1.08(0.88-1.32)$ & .49 & & \\
\hline Red blood cell transfusion & $3.99(2.53-6.30)$ & $<.0001$ & & \\
\hline Fresh frozen plasma transfusion & $7.36(3.95-13.72)$ & $<.0001$ & & \\
\hline Platelet transfusion & $13.61(6.81-27.21)$ & $<.0001$ & $2.63(1.13-6.15)$ & .02 \\
\hline Cryoprecipitate & $<0.001(<0.001->999.99)$ & .98 & & \\
\hline Bispectral index, per unit increase & $0.98(0.96-1.01)$ & .27 & & \\
\hline MAC, per percentage increase & $0.10(0.03-0.32)$ & .0002 & & \\
\hline Duration of surgery, per 30-min increase & $0.92(0.86-0.98)$ & .008 & & \\
\hline Year of surgery, per year increase & $0.82(0.68-0.99)$ & .04 & $0.79(0.64-0.95)$ & .03 \\
\hline Postoperative acute kidney injury & $6.16(4.14-9.15)$ & $<.0001$ & 2.39 (1.54-3.71) & .0001 \\
\hline
\end{tabular}
arterial pressure. 
mortality. ${ }^{15,16,18,32,33}$ Panagiotakos et $\mathrm{al}^{12}$ found that in 12,763 men, elevated PP was a significant predictor of coronary artery disease, as well as cardiovascular- and stroke-related mortality. In a study of 2152 elderly subjects, elevated PP was a strong predictor of coronary artery disease, congestive heart failure, and overall mortality. ${ }^{18}$ Further, elevated PP showed a stronger association with these cardiovascular end points compared with the mean blood pressure and systolic blood pressure.

Subsequent perioperative studies found that elevated PP is a risk factor for mortality, renal failure, stroke, and cardiovascular complications in cardiac surgery patients. ${ }^{20,21,34-36}$ In a study of 5436 patients undergoing coronary artery bypass graft (CABG) surgery, we reported that patients with elevated PP (>80 mm Hg) were more likely to suffer neurologic, renal, and cardiovascular complications and were more likely to die of these causes. ${ }^{21}$ Similarly, in a retrospective study of 973 patients, our team found that increased perioperative PP was associated with a poor long-term survival rate after $\mathrm{CABG}$ surgery. ${ }^{34}$ Likewise, Aboyans et $\mathrm{al}^{35}$ conducted a prospective study of 1022 patients who underwent elective CABG surgery and reported that subjects with an elevated PP ( $\geq$ $70 \mathrm{~mm} \mathrm{Hg}$ ) had higher rates of 30-day postoperative mortality, myocardial infarction, and cerebrovascular events. Benjo et $\mathrm{al}^{36}$ also found that the probability of stroke-free survival after cardiac surgery was significantly lower in patients with elevated PP (>72 $\mathrm{mm} \mathrm{Hg}$ ).

Of note, we also reported that in patients undergoing cardiac surgery, ${ }^{20}$ an incremental rise in baseline PP of 20 $\mathrm{mm} \mathrm{Hg}$ increased the risk for renal composite outcomes by $49 \%$, that is, renal dysfunction or renal failure, and death from renal causes. In the current study, we hypothesized that elevated preoperative PP increases the risk for postoperative AKI and 30-day mortality in noncardiac surgery patients. Similarly to the previous studies in cardiac surgical patients, ${ }^{20,21}$ in our heterogeneous noncardiac surgical cohort, we also observed that elevated preoperative PP showed a strong association with postoperative AKI. However, the lack of direct association between elevated preoperative PP and 30-day mortality and more severe stages of AKI in our study compared with studies conducted in cardiac surgical patients could be explained as follows: a relatively very low incidence of 30-day mortality $(1.14 \%)$; low incidences of AKI stages II $(8.4 \%)$ and III (4.2\%); younger surgical cohort (mean age of 55.9 years); heterogeneity of surgical procedures; and by variation in patient factors or comorbidities (ie, systemic micro and macrovascular disease) between cardiac and noncardiac surgical patients. Indeed the mean PP in our study was $56 \mathrm{~mm} \mathrm{Hg}$ with only $8.5 \%$ of patients having baseline PP $>80 \mathrm{~mm} \mathrm{Hg}$. The pathogenesis of PP is progressive with age and its relation to cerebral, cardiac, and renal ischemic events as well as mortality is most notable in older persons (>65 years)..$^{20,21}$

Hypertension is a well-known risk factor for perioperative outcomes and a complex marker for underlying cardiovascular disease. ${ }^{37,38}$ Early studies focused on the role of systolic, mean, and diastolic components of blood pressure. ${ }^{39,40}$ More recent evidence indicates that an increase in the pulsatile nature of propagated pressure waves throughout the vascular tree provides an important information about cardiovascular risk. ${ }^{20,41}$ When the aorta becomes stiff and loses compliance, its ability to compensate for low-pressure and low-flow periods throughout the cardiac cycle diminishes. There is also an evidence that organs in close proximity to the aorta, such as the brain and kidneys, may undergo microvascular changes because of the mechanical pressure and trauma. ${ }^{13}$ As a result, normal autoregulatory physiology is disrupted and arterial blood flow becomes highly pressure-dependent in patients with PP hypertension. ${ }^{20}$ Therefore, an appreciation for the presence of impaired autoregulation in elderly hypertensive patients undergoing noncardiac surgery with general anesthesia is important. ${ }^{42}$

Elevated PP is caused by multiple changes in the walls of central arteries, and it is a marker for conduit vessel stiffness and an indicator of the rate of pressure wave propagation and reflection within the arterial system. ${ }^{43}$ When waves generated from left ventricular ejection return to central circulation during late systole rather than during early diastole, systolic pressure increases and diastolic pressure decreases, which translates to the increased left ventricular afterload and decreased coronary artery perfusion during diastole. ${ }^{41}$ Constant exposure of conduit vessels to the reflected pressure waves leads to loss of the endothelial elastic elements, conduit vessel stiffness, and dilation. ${ }^{44}$ Thus, individuals with arterial stiffness are at high risk for myocardial dysfunction and myocardial ischemia. ${ }^{41}$

The brain and kidney are significantly affected by arteriolar adaptive changes resulting from conduit vessel stiffness. Of note, arterial stiffness and PP can also be associated with renal dysfunction independent of age, in the nonsurgical setting ${ }^{45}$ and in patients undergoing cardiac surgery. ${ }^{20}$ As such, advanced age, although a direct marker for degenerative changes in many organ functions, has not been consistently defined as an independent predictor of AKI in noncardiac surgery patients.?

Studies in nonsurgical populations suggest that elevated PP may be modified through exercise, diet, caloric restriction, and weight loss. ${ }^{46}$ However, we do not yet know the extent to which the risk associated with elevated PP or its pathophysiologic consequences for organ perfusion can be acutely modified in the perioperative period. Further studies are therefore needed to better define the exact mechanisms of postoperative AKI in patients with elevated PP, and how preoperative prevention or management of elevated PP and/or these mechanisms can be modified in the perioperative period.

In this study, we confirmed the value of many previously described risk factors for predicting postoperative AKI or 30-day mortality after noncardiac surgery. In particular, higher categories in the ASA physical status classification system, ${ }^{47}$ higher Cleveland Clinic Risk Index scores, ${ }^{48}$ certain aggregates of diagnosis and surgical procedure categories, lower preoperative hemoglobin concentration levels, ${ }^{49}$ and intraoperative use of norepinephrine ${ }^{9}$ were consistently significant predictors of postoperative AKI and 30-day mortality in our risk-adjusted analyses. Intriguingly we observed that most of these risk factors were associated with the elevated PP. In spite of this elevated PP was not independently associated with 
30-day mortality. In fact, in this cohort, we observed that postoperative AKI and 30-day mortality did not share the same risk factors. Male sex, black race, history of antihypertensive medication use, intraoperative cardiovascular medication use, and cumulative duration of MAP $<55 \mathrm{~mm} \mathrm{Hg}$ increased the risk for postoperative AKI, but not for 30-day mortality. Nevertheless, postoperative AKI was a strong predictor of 30-day mortality. Therefore, in an indirect way, measures that decrease the incidence and severity of postoperative AKI may potentially reduce the risk for 30-day mortality.

The ability to identify patients at risk for perioperative mortality has greatly improved in recent years. We observed that a more recent year of surgery was associated with a significantly decreased risk for 30-day mortality, which could reflect improvements in perioperative management of patients undergoing noncardiac surgery. However, our findings also indicated that a more recent year of surgery was associated with a higher risk for postoperative AKI. Thus, more work is needed to identify and address modifiable risk factors so that perioperative morbidity and mortality outcomes can be improved. ${ }^{11}$

\section{Limitations}

Because of its retrospective design, our study has several limitations. Information on clinical risk factors of postoperative AKI and 30-day mortality were not prospectively collected. Instead, data on clinical risk factors, medication use, and laboratory values were retrieved from electronic medical records, electronic intraoperative charts, and physician documentation. Thus, effects and the magnitude of effects of certain risk factors, medications, and laboratory data may have been biased. Nevertheless, their predictive values and effect sizes were similar to published findings from other studies. ${ }^{3,22}$

Further, the generalizability of our observations could be limited since our study was performed in a single tertiary center. In particular, the frequency of $\mathrm{AKI},{ }^{2,3}$ but not the frequency of mortality, ${ }^{50}$ observed in our study was higher than reported from recent large-scale studies. Several reasons could account for this discrepancy in the frequency of AKI including patient characteristics, intraoperative management, and use of the KDIGO definition of AKI.

In our study, preoperative PP classification was based on the average difference between the systolic and diastolic blood pressures that were measured while many patients were awake before anesthesia induction, therefore, baseline PP could also have been falsely elevated because of preoperative anxiety and catecholamine release, which results in the increased blood pressure in the operating room and diurnal change in blood pressure, an important source of variability in measurements. ${ }^{51}$ To partially overcome these limitations, we therefore computed mean preoperative PP based on the average of the first 5 recorded values using a previously validated methodology. ${ }^{21}$ We observed that the mean systolic blood pressure was $131.6 \pm 21.2 \mathrm{~mm} \mathrm{Hg}$, diastolic blood pressure was $75.7 \pm 13.7 \mathrm{~mm} \mathrm{Hg}$, and the mean PP was $55.9 \pm 16.5 \mathrm{~mm} \mathrm{Hg}$. Even after we adjusted for baseline and clinical characteristics, our results still showed a statistically significant and incremental risk for AKI with increasing baseline PP. Thus, the potential risk for an error in PP classification was likely minimal.
In addition, pre- and intraoperative techniques for blood pressure management or anesthetic technique were not standardized, given the retrospective nature of the study. Therefore, future investigations should focus on effects of preoperative and anesthetic management on PP.

Further, given the retrospective nature of our study were not able to ascertain with certainty how many of the patients with postoperative AKI required renal replacement therapy after surgery. Thus, in our study, we did not analyze the effect of renal replacement therapy on the risk of 30-day mortality.

Finally, aortic valve regurgitation, which could lower diastolic blood pressure and increase PP, was not systematically ruled out in our study. However, given that the age-adjusted prevalence of aortic valve regurgitation in the general population is only $0.3 \%$ in subjects aged between 55 and $64,,^{52}$ the likelihood of this being an important factor is low.

In summary, this study suggests an independent association between increased preoperative PP and postoperative AKI after noncardiac surgery. Our findings therefore suggest the need to reevaluate risk assessment models and reinforce the importance of vigilant blood pressure monitoring and management in the perioperative setting.

\section{ACKNOWLEDGMENTS}

The authors thank Betsy W. Hale, BSc, (Data Analyst, Department of Anesthesiology, Duke University Medical Center, Durham, NC) for her help with data retrieval and database building, Ishwori Dhakal, MSc, (Statistician Department of Anesthesiology, Duke University Medical Center, Durham, NC) for his help with statistical analysis. They also thank Annette Lombard and Shoji Moto (Research Associates, Department of Anesthesiology, Duke University Medical Center) for their help with preparing the analysis and writing the manuscript. Finally, we thank Kathy Gage, BS, (Research Development Associate, Department of Anesthesiology, Duke University Medical Center) for her editorial contributions to the manuscript.

Dr. Karhausen has received a grant from the American Heart Association, Dallas, Texas (grant no. 15SDG25080046).

\section{DISCLOSURE}

Name: Adriana D. Oprea, MD.

Contribution: This author helped design the study, conduct the study, and write the manuscript.

Name: Frederick W. Lombard, MB, ChB, FANZCA.

Contribution: This author helped design the study, conduct the study, and write the manuscript.

Name: Wen-Wei Liu, MSc.

Contribution: This author helped design the study, conduct the study, analyze the data, and write the manuscript.

Name: William D. White, MSc.

Contribution: This author helped design the study, conduct the study, analyze the data, and write the manuscript.

Name: Jorn A. Karhausen, MD.

Contribution: This author helped write the manuscript.

Name: Yi-Ju Li, PhD.

Contribution: This author helped analyze the data and write the manuscript.

Name: Timothy E. Miller, MB, ChB, FRCA.

Contribution: This author helped write the manuscript.

Name: Solomon Aronson, MD, MBA.

Contribution: This author helped write the manuscript.

Name: Tong J. Gan, MD, MHS, FRCA. 
Contribution: This author helped design the study, conduct the study, and write the manuscript.

Name: Manuel L. Fontes, MD.

Contribution: This author helped design the study, conduct the study, and write the manuscript.

Name: Miklos D. Kertai, MD, PhD.

Contribution: This author helped design the study, conduct the study, analyze the data, and write the manuscript.

This manuscript was handled by: Sorin J. Brull, MD.

\section{REFERENCES}

1. Garzotto F, Piccinni P, Cruz D, et al; NEFROINT Investigation Group. RIFLE-based data collection/management system applied to a prospective cohort multicenter Italian study on the epidemiology of acute kidney injury in the intensive care unit. Blood Purif. 2011;31:159-171.

2. Biteker M, Dayan A, Tekkeşin Aİ, et al. Incidence, risk factors, and outcomes of perioperative acute kidney injury in noncardiac and nonvascular surgery. Am J Surg. 2014;207:53-59.

3. Sun LY, Wijeysundera DN, Tait GA, Beattie WS. Association of intraoperative hypotension with acute kidney injury after elective noncardiac surgery. Anesthesiology. 2015;123:515-523.

4. Teixeira C, Rosa R, Rodrigues N, et al. Acute kidney injury after major abdominal surgery: a retrospective cohort analysis. Crit Care Res Pract. 2014;2014:132175.

5. Kheterpal S, Tremper KK, Heung M, et al. Development and validation of an acute kidney injury risk index for patients undergoing general surgery: results from a national data set. Anesthesiology. 2009;110:505-515.

6. Demyttenaere S, Feldman LS, Fried GM. Effect of pneumoperitoneum on renal perfusion and function: a systematic review. Surg Endosc. 2007;21:152-160.

7. Abelha FJ, Botelho M, Fernandes V, Barros H. Determinants of postoperative acute kidney injury. Crit Care. 2009;13:R79.

8. Chertow GM, Burdick E, Honour M, Bonventre JV, Bates DW. Acute kidney injury, mortality, length of stay, and costs in hospitalized patients. J Am Soc Nephrol. 2005;16:3365-3370.

9. Kheterpal S, Tremper KK, Englesbe MJ, et al. Predictors of postoperative acute renal failure after noncardiac surgery in patients with previously normal renal function. Anesthesiology. 2007;107:892-902.

10. James PA, Oparil S, Carter BL, et al. 2014 evidence-based guideline for the management of high blood pressure in adults: report from the panel members appointed to the Eighth Joint National Committee (JNC 8). JAMA. 2014;311:507-520.

11. Kertai MD, Gan TJ. Screening for high blood pressure in the perioperative setting: the role of anesthesiologists in future cardiovascular risk management. Anesth Analg. 2015;121:1439-1440.

12. Panagiotakos DB, Kromhout D, Menotti A, et al. The relation between pulse pressure and cardiovascular mortality in 12,763 middle-aged men from various parts of the world: a 25-year follow-up of the seven countries study. Arch Intern Med. 2005;165:2142-2147.

13. O'Rourke MF, Safar ME. Relationship between aortic stiffening and microvascular disease in brain and kidney: cause and logic of therapy. Hypertension. 2005;46:200-204.

14. Safar ME, Levy BI, Struijker-Boudier H. Current perspectives on arterial stiffness and pulse pressure in hypertension and cardiovascular diseases. Circulation. 2003;107:2864-2869.

15. Blacher J, Staessen JA, Girerd X, et al. Pulse pressure not mean pressure determines cardiovascular risk in older hypertensive patients. Arch Intern Med. 2000;160:1085-1089.

16. Franklin SS, Khan SA, Wong ND, Larson MG, Levy D. Is pulse pressure useful in predicting risk for coronary heart disease? The Framingham Heart Study. Circulation. 1999;100:354-360.

17. Klassen PS, Lowrie EG, Reddan DN, et al. Association between pulse pressure and mortality in patients undergoing maintenance hemodialysis. JAMA. 2002;287:1548-1555.

18. Vaccarino V, Holford TR, Krumholz HM. Pulse pressure and risk for myocardial infarction and heart failure in the elderly. J Am Coll Cardiol. 2000;36:130-138.

19. Wilkinson IB, Cockcroft JR. Mind the gap: pulse pressure, cardiovascular risk, and isolated systolic hypertension. Am J Hypertens. 2000;13:1315-1317.
20. Aronson S, Fontes ML, Miao Y, Mangano DT. Risk index for perioperative renal dysfunction/failure: critical dependence on pulse pressure hypertension. Circulation. 2007;115:733-742.

21. Fontes ML, Aronson S, Mathew JP, et al. Pulse pressure and risk of adverse outcome in coronary bypass surgery. Anesth Analg. 2008;107:1122-1129.

22. Mazzeffi M, Flynn B, Bodian C, Bronheim D. Preoperative arterial pulse pressure has no apparent association with perioperative mortality after lower extremity arterial bypass. Anesth Analg. 2012;114:1170-1176.

23. Asopa A, Jidge S, Schermerhorn ML, Hess PE, Matyal R, Subramaniam B. Preoperative pulse pressure and major perioperative adverse cardiovascular outcomes after lower extremity vascular bypass surgery. Anesth Analg. 2012;114:1177-1181.

24. Kertai MD, White WD, Gan TJ. Cumulative duration of "triple low" state of low blood pressure, low bispectral index, and low minimum alveolar concentration of volatile anesthesia is not associated with increased mortality. Anesthesiology. 2014;121:18-28.

25. Sessler DI, Sigl JC, Manberg PJ, Kelley SD, Schubert A, Chamoun NG. Broadly applicable risk stratification system for predicting duration of hospitalization and mortality. Anesthesiology. 2010;113:1026-1037.

26. Reich DL, Bennett-Guerrero E, Bodian CA, Hossain S, Winfree W, Krol M. Intraoperative tachycardia and hypertension are independently associated with adverse outcome in noncardiac surgery of long duration. Anesth Analg. 2002;95:273-277.

27. Sickeler R, Phillips-Bute B, Kertai MD, et al. The risk of acute kidney injury with co-occurrence of anemia and hypotension during cardiopulmonary bypass relative to anemia alone. Ann Thorac Surg. 2014;97:865-871.

28. Nickalls RW, Mapleson WW. Age-related iso-MAC charts for isoflurane, sevoflurane and desflurane in man. Br J Anaesth. 2003;91:170-174.

29. Kidney Disease: Improving Global Outcomes (KDIGO) Acute Kidney Injury Work Group. KDIGO clinical practice guideline for acute kidney injury. Kidney Inter. 2012;2:1-138.

30. Hanley JA, McNeil BJ. The meaning and use of the area under a receiver operating characteristic (ROC) curve. Radiology. 1982;143:29-36.

31. Lemeshow S, Hosmer DW Jr. A review of goodness of fit statistics for use in the development of logistic regression models. Am J Epidemiol. 1982;115:92-106.

32. Benetos A, Safar M, Rudnichi A, et al. Pulse pressure: a predictor of long-term cardiovascular mortality in a French male population. Hypertension. 1997;30:1410-1415.

33. Benetos A, Rudnichi A, Safar M, Guize L. Pulse pressure and cardiovascular mortality in normotensive and hypertensive subjects. Hypertension. 1998;32:560-564.

34. Nikolov NM, Fontes ML, White WD, et al. Pulse pressure and long-term survival after coronary artery bypass graft surgery. Anesth Analg. 2010;110:335-340.

35. Aboyans V, Frank M, Nubret K, Lacroix P, Laskar M. Heart rate and pulse pressure at rest are major prognostic markers of early postoperative complications after coronary bypass surgery. Eur J Cardiothorac Surg. 2008;33:971-976.

36. Benjo A, Thompson RE, Fine D, et al. Pulse pressure is an ageindependent predictor of stroke development after cardiac surgery. Hypertension. 2007;50:630-635.

37. Fleisher LA, Fleischmann KE, Auerbach AD, et al; American College of Cardiology; American Heart Association. 2014 ACC/ AHA guideline on perioperative cardiovascular evaluation and management of patients undergoing noncardiac surgery: a report of the American College of Cardiology/American Heart Association Task Force on practice guidelines. J Am Coll Cardiol. 2014;64:e77-e137.

38. Verdecchia P, Angeli F. Natural history of hypertension subtypes. Circulation. 2005;111:1094-1096.

39. Chertow GM, Levy EM, Hammermeister KE, Grover F, Daley J. Independent association between acute renal failure and mortality following cardiac surgery. Am J Med. 1998;104:343-348.

40. Mangano CM, Diamondstone LS, Ramsay JG, Aggarwal A, Herskowitz A, Mangano DT. Renal dysfunction after myocardial revascularization: risk factors, adverse outcomes, and 
hospital resource utilization. The Multicenter Study of Perioperative Ischemia Research Group. Ann Intern Med. 1998;128:194-203.

41. Dart AM, Kingwell BA. Pulse pressure-a review of mechanisms and clinical relevance. J Am Coll Cardiol. 2001;37:975-984.

42. Drummond JC. The lower limit of autoregulation: time to revise our thinking? Anesthesiology. 1997;86:1431-1433.

43. Adji A, O'Rourke MF, Namasivayam M. Arterial stiffness, its assessment, prognostic value, and implications for treatment. Am J Hypertens. 2011;24:5-17.

44. Ichigi $\mathrm{Y}$, Takano $\mathrm{H}$, Umetani $\mathrm{K}$, et al. Increased ambulatory pulse pressure is a strong risk factor for coronary endothelial vasomotor dysfunction. J Am Coll Cardiol. 2005;45:1461-1466.

45. Briet M, Bozec E, Laurent $S$, et al. Arterial stiffness and enlargement in mild-to-moderate chronic kidney disease. Kidney Int. 2006;69:350-357.

46. Najjar SS, Scuteri A, Lakatta EG. Arterial aging: is it an immutable cardiovascular risk factor? Hypertension. 2005;46:454-462.

47. Daley J, Khuri SF, Henderson W,et al. Risk adjustment of the postoperative morbidity rate for the comparative assessment of the quality of surgical care: results of the National Veterans Affairs Surgical Risk Study. J Am Coll Surg. 1997;185:328-340.
48. Sessler DI, Sigl JC, Kelley SD, et al. Hospital stay and mortality are increased in patients having a "triple low" of low blood pressure, low bispectral index, and low minimum alveolar concentration of volatile anesthesia. Anesthesiology. 2012;116:1195-1203.

49. Walsh M, Garg AX, Devereaux PJ, Argalious M, Honar H, Sessler DI. The association between perioperative hemoglobin and acute kidney injury in patients having noncardiac surgery. Anesth Analg. 2013;117:924-931.

50. Kertai MD, Palanca BJ, Pal N, et al; B-Unaware Study Group. Bispectral index monitoring, duration of bispectral index below 45 , patient risk factors, and intermediate-term mortality after noncardiac surgery in the B-Unaware Trial. Anesthesiology. 2011;114:545-556.

51. Den Hond E, Celis H, Vandenhoven G, O'Brien E, Staessen JA; THOP investigators. Determinants of white-coat syndrome assessed by ambulatory blood pressure or self-measured home blood pressure. Blood Press Monit. 2003;8:37-40.

52. Nkomo VT, Gardin JM, Skelton TN, Gottdiener JS, Scott CG, Enriquez-Sarano M. Burden of valvular heart diseases: a population-based study. Lancet. 2006;368:1005-1011. 